\title{
The perfection of the construction of a combined cutting tool on the basis of the results of mathematical modelling of working cutting processes in RecurDyn
}

\author{
Vladimir Poddubny ${ }^{1}$, Yuri Kryazhev ${ }^{1}$, and Eugene Gorin ${ }^{1, *}$ \\ ${ }^{1}$ Altai State Technical University (ASTU), 46 Lenin St., Barnaul, 656038, Russia
}

\begin{abstract}
As the title implies the article describes how to optimize the construction of a combined cutting tool on the example of developed design of the face milling cutter with regulable rigidity of damping elements in order to improve the vibration resistance of the cutting process. RecurDyn is proposed, which is widely used for creating models of different mechanical systems, their analysis and optimization of construction, uses the ideology of visual object-oriented programming and computer research of volume solid-state models. Much attention is given to the description of the mechanical and mathematical model of the face milling cutter in RecurDyn and the results of mathematical modeling of the face milling cutter with damping elements, consisting of individual elements, with the possibility of program controlling its operation in the process of cutting. The applying of RecurDyn made it possible to carry out a complex assessment of influence of separate elements of a design of the combined cutting tool on quantitative and qualitative parameters of milling process and to define optimal values of the input and output parameters of technological process of machining for various damping elements.
\end{abstract}

\section{The modeling of mechanical systems in RecyrDun}

One of the most important stages in the design of cutting tools is the development of their mathematical models and subsequent modeling for a preliminary assessment of the quality of functioning, in order to determine the degree of influence of the produced structural or technological changes on the qualitative and quantitative parameters of the cutting process.

In RecyrDun the ideology of visual object-oriented programming is used. This software is designed to create models of various mechanical systems, their analysis and optimization.

The core module of the RecyrDunProfessional consists of Body, Joint, Force and Contact.Body makes it possible to include solid bodies of correct geometric shape in the structure (ellipsoid, cylinder, parallelepiped, torus, cone). Mass geometric characteristics are determined by body sizes and material densities, which are set by the user. Joint contains a set of connections providing various movements of the connected system bodies relatively each other. Force allows to describe the various forces acting on the bodies of a mechanical system (the elastic force of Spring with a given rigidity and damping, the force of Axial, acting in the given direction and described by the analytical expression, and many others). The great advantage of RecyrDun in comparison with the most known programs for modeling multibody mechanical systems is the possibility of describing contacts between the bodies of the system without an analytical description of this interaction. Contact gives us this possibility. The interface of contact interaction allows setting the direction of force interaction, stiffness, and damping. Another advantage of RecyrDun is the possibility to include the deforming finite element bodies in the structure of solid bodies system, to make the contact between solid and deformed bodies. It is provided by Flexible.

It is possible to import 3D models from other software (CATIA, Parasolid, SolidWorks).

\section{The improving the vibration resistance of the cutting process by using combined cutting tools with regular rigidity}

The vibrations of the technological system, which occur during the cutting process have a great influence on the accuracy of machining and the firmness of the cutting tool. When the fluctuations of the cutting tool appear relatively to processed surface its firmness decreases and there are some cross-section errors on the workpiece, a sinuosity develops and the roughness of the processed surface increases. At the same time the productivity decreases, because of the increase in idle time of the equipment, connected with the replacement and adjustment of the tool. The vibrations generated by machining after reaching certain amplitude values are further strengthened due to the instability of the cutting forces at incision and pushing of the cutting tool, as well as by changing the true cutting angles with relative oscillations of the system elements, which leads to changes in the cutting force and the movements caused by it. At small rigidity of technological system, these sources

*Corresponding author: evgenijgorin@gmail.com 
can not only enhance the oscillations that have arisen, but also become the reason of their emergence. Due to the harmful effects of the vibrations of the technological system on the accuracy, productivity and firmness of the cutting tool at the design of technological processes, the construction of machining attachments and the cutting tool, the task of complete elimination of danger of vibrations or reducing them to the minimum acceptable level is set. The most effective means of struggling vibrations and enhancing the vibration resistance of a technological system is the regulation of rigidity of all elements of a dynamic system, where the most important link in this system is "detail-tool". The degree of stability of the technological system determines its ability to dissipate the energy introduced by the external action, and can be estimated from the rapidity of attenuation of deviations in transition processes [1]. The greater the degree of stability in this particular component of the dynamic system, the faster the decay of transition process of incision of the cutting teeth, the less deviation in the set cutting process.

In this article we consider the reducing of vibrational loads on technological system by absorbing the energy of the oscillating motion of the face milling cutter and controlling the vibration resistance of the cutting tool by increasing its damping properties. At the department of "Technology of Mechanical Engineering" Altai State Technical University the construction of a face mill is developed (a figure 1), in which rubber inserts (damping elements) are used to regulate its rigidity, the number of which can vary depending on the required cutting conditions and the natural frequency of the cutting tool (patent No. 2559078). The main advantage of the proposed method is its wide universality and, as a result, the possibility of its application not only for mills, but also for other types of cutting tools. Damping elements that regulate the rigidity of the face milling cutter can be selected by material and design, taking into account the dynamic characteristics of the technological system, which increases the efficiency of its use.

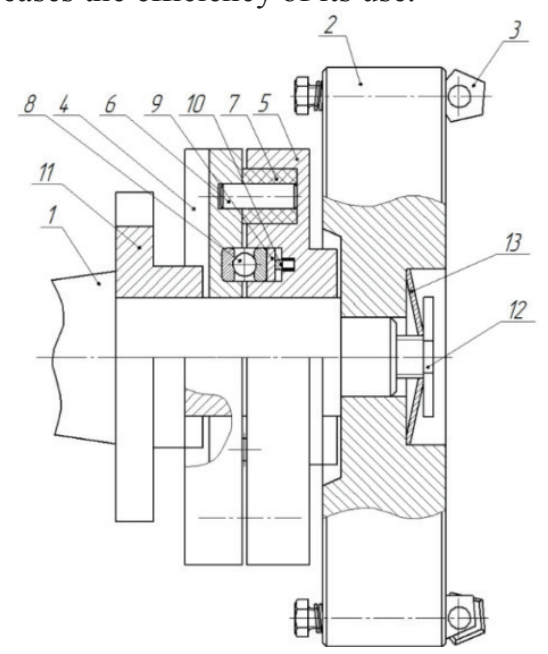

Fig. 1. Combined face mill with damping elements. $1-$ mandrel; 2- milling cutter body; 3 - cutting plates; 4 - top ring of knot of damping; 5 - low ring of knot of damping; 6 - pin; 7 - elastic damping elements; 8 - thrust bearing; 9 - distance washer; 10 - elastic figured washer; 11 - lead; 12 - adjusting screw; 13 - spring washer

\section{Mathematical model of calculation of vibration characteristics for the processes of face milling}

The tool (milling cutter) is represented as a single-mass model with 5 degrees of freedom, which corresponds to the given mass-rigid characteristics.

Figure 2 shows the scheme of the tool and degree of freedom of its dynamic model: $x, y$ - linear movements relative to the principal axes ox, oy; $\Psi_{x}, \Psi_{y}$ - angular movements in the planesxoz и уоz; $\theta$ - amount of twist; $\omega$ - angular speed of rotation of the tool; D - diameter of a mill; $\mathrm{S}_{Z}$ - feed per tooth; $\varphi-$ mill angle of rotation; $\varphi_{\mathrm{P}}$ - central working corner of a mill; $\varphi_{\text {en }}$ - mill angle of entry.

The system of the differential equations of process:

$$
\left\{\begin{array}{l}
m_{X} \frac{\partial^{2} x}{\partial t^{2}}+\eta_{X} \frac{\partial x}{\partial t}+C_{X} x=P_{X}\left(x, y, \psi_{X}, \psi_{Y}, \theta, t\right) \\
m_{Y} \frac{\partial^{2} y}{\partial t^{2}}+\eta_{Y} \frac{\partial y}{\partial t}+C_{Y} x=P_{Y}\left(x, y, \psi_{X}, \psi_{Y}, \theta, t\right) \\
I_{X} \frac{\partial^{2} \psi_{X}}{\partial t^{2}}+\eta_{\psi_{X}} \frac{\partial \psi_{X}}{\partial t}+C_{\psi_{X}} \psi_{X}=M_{X}\left(x, y, \psi_{X}, \psi_{Y}, \theta, t\right) \\
I_{Y} \frac{\partial^{2} \psi_{Y}}{\partial t^{2}}+\eta_{\psi_{Y}} \frac{\partial \psi_{Y}}{\partial t}+C_{\psi_{Y}} \psi_{Y}=M_{Y}\left(x, y, \psi_{X}, \psi_{Y}, \theta, t\right) \\
I_{\theta} \frac{\partial^{2} \theta}{\partial t^{2}}+\eta_{\theta} \frac{\partial \theta}{\partial t}+C_{\theta} \theta=M_{\theta}\left(x, y, \psi_{X}, \psi_{Y}, \theta, t\right)
\end{array}\right.
$$

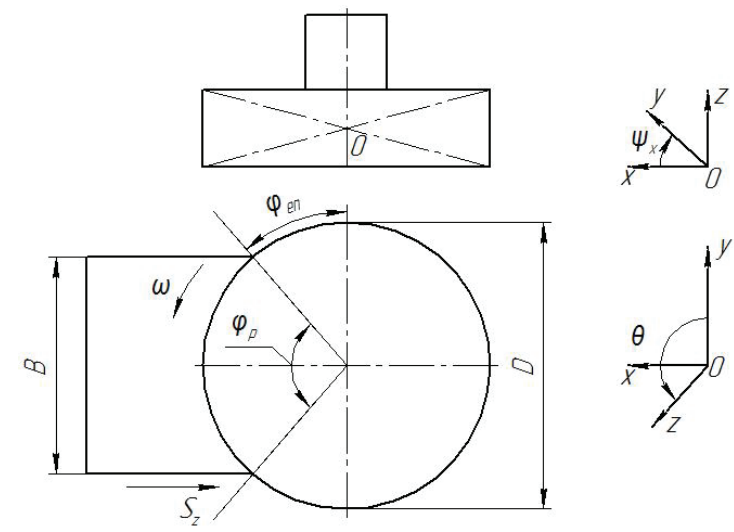

Fig. 2. Scheme of operation of the tool and degree of freedom of dynamic model.

where $m_{X}, m_{Y}$ - given masses for the directionsox, oy; $l_{x}, l_{y}, l_{\theta}-$ given moments of inertia of the tool relative to the main axes ox, oy, oz $; \eta_{x}, \eta_{y}, \eta_{\psi x}, \eta_{\psi y}, \eta_{\theta}-$ damping ratio; $C_{x}, C_{y}, C_{\psi y x}, C_{\psi y}, C_{\theta}-$ given rigidity; $P_{x}, P_{y}, M_{x}, M_{y}$, $M_{\theta}$ - according to effort in the directionox, oyand external moments relative to the main axes ox, oy, oz; $t$ - time.

The interaction between the tool and the workpiece during milling is replaced by the effect on the cutting force tool system: axial $-P_{O}$, radial $-P_{R}$, tangential $-\mathrm{P} \tau$. Depending on the type of material and processing conditions, the following relationships are obtained from the experimental results for cutting forces:

$$
P_{R} / P_{\tau}=0,3 \div 0,4 ; P_{O} / P_{\tau}=0,4 \div 0,45 \text {, }
$$




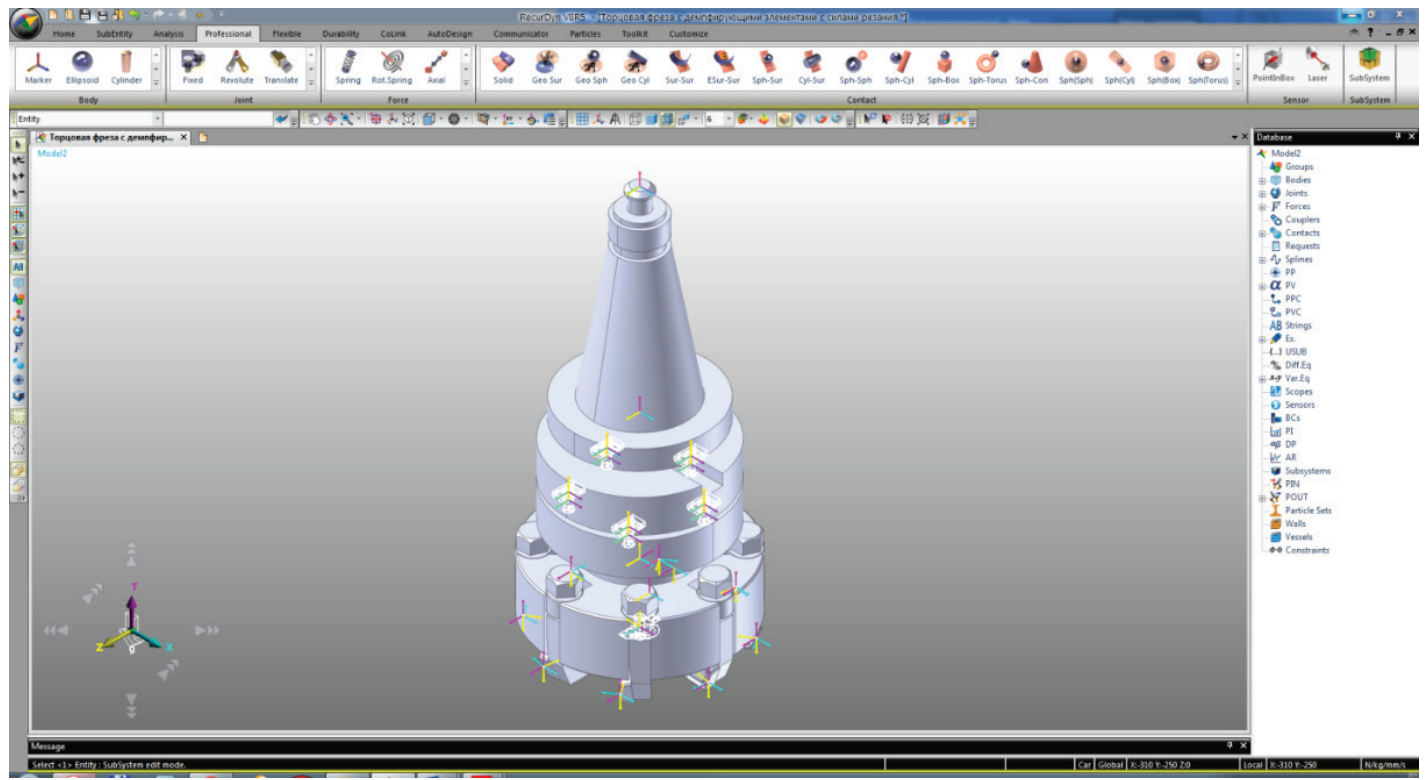

Fig. 3. RecyrDun program window with imported solid model of face milling cutter with damping elements.

\section{Results of modeling of working processes of cutting by a face mill with dampening elements}

To work in RecyrDun a solid model of the face mill should be used, created in Solidworks Version 2016.

The face milling process was simulated with the following initial data: $D=120 \mathrm{~mm}$ - diameter of a mill; $\mathrm{z}=8$ - number of teeth; $\mathrm{t}=1 \mathrm{~mm}$ - cutting depth; $\mathrm{B}=85 \mathrm{~mm}-$ cutting width; $\mathrm{S}_{\mathrm{z}}=0,1 \mathrm{~mm} /$ tooth - feed; $\mathrm{n}=500 \mathrm{rpm}-$ frequency of rotation of a mill; $\mathrm{v}=188,4 \mathrm{~m} / \mathrm{m}$ - milling speed. Within the conducted researches process of cutting was modelled with use of the damping elements from rubber (HL 3.1) and steel (St45). Characteristics of knot of damping - radial rigidity and damping were set in baseParametric Value List (Figure 4).

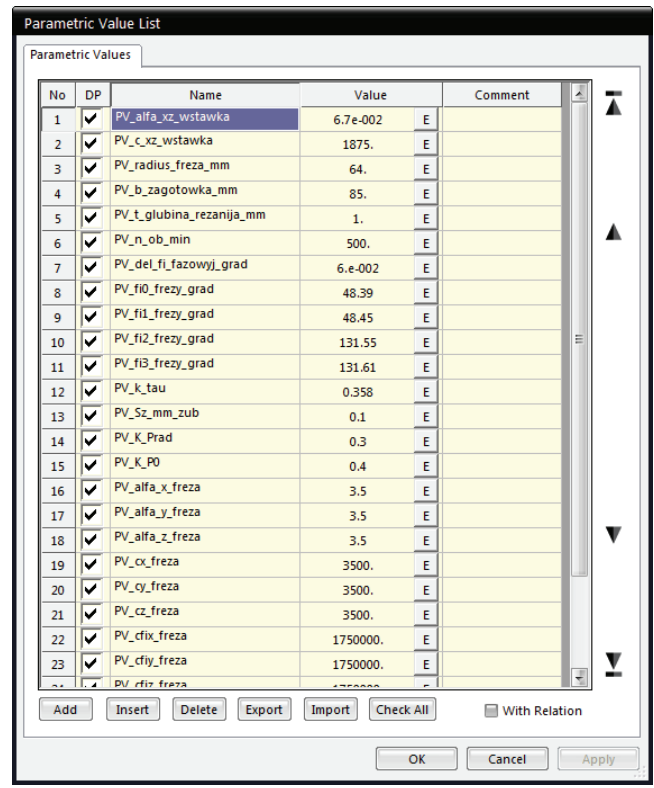

Fig. 4. Initial parameters of modeling of process of milling in RecyrDun
The research in Analisis made it possible to simulate the dynamic state of the combined face mill in the process of cutting steel workpiece of specified sizes and physical and mechanical properties and to carry out a dynamic analysis for various parameters of the milling regime.In this case, RecurDyn, taking into account the connections between the elements, develops equations that connect the reaction with the property of the material, limit and load. After this RecurDyn ordering the equations in a big system of the joint algebraic equations, finds unknown.

During the research Dynamic/Kinematic Analysis graphs of vibration movements along the Z-axis of the combined face milling cutter were obtained while milling the steel workpiece with various damping elements. Figure 5 shows an example of a comparison of the Z-axis oscillation curves for face milling for inserts of rubber and steel.

As can be seen from the graphs shown in Fig. 6, the magnitude of the vibration movements along the Zaxisfor milling with damping elements made of steel is greater than the value of the vibration movements for milling with damping elements made of rubber by 20 $30 \%$ during the processing time. In this case, the milling process with damping elements made of rubber is stable, since the swing amplitude along the $\mathrm{Z}$ axis is stable.

The results of the simulation in RecyrDun correlate with the results of the experimental work carried out on the vertical 5-axis Mazak Variaxis 630 machining center. The workpiece from $30 \mathrm{HGSN} 2 \mathrm{~A}-\mathrm{VD}$ was processed by a projected face milling cutter on the cutting modes: $\mathrm{t}=1$ mm; - cutting depth; $\mathrm{S}_{\mathrm{z}}=0,1 \mathrm{~mm} /$ tooth - feed; $\mathrm{n}=500 \mathrm{rpm}$ - frequency of rotation of a mill; $\mathrm{v}=188,4 \mathrm{~m} / \mathrm{m}$ - milling speed.

On the studied parameters of cutting modesvalue of a roughness of the processed surface in the Ra parameter has decreased by $19,2 \%$ for a combined face mill with the damping elements from rubber in comparison with a roughness of the processed surface worked by a mill with the damping elements made of steel. In this case, the vibration movement during the modeling in RecyrDun 
according to standard deviations and swings with a high accuracy is related to the roughness of the processed surfaces obtained during the experimental studies. Thus, in the process of face milling with a mill with rubber inserts, the oscillations of the cutting tool are reduced, which decrease the roughness of the processed surface in the same ratio as in the modeling in RecyrDun.

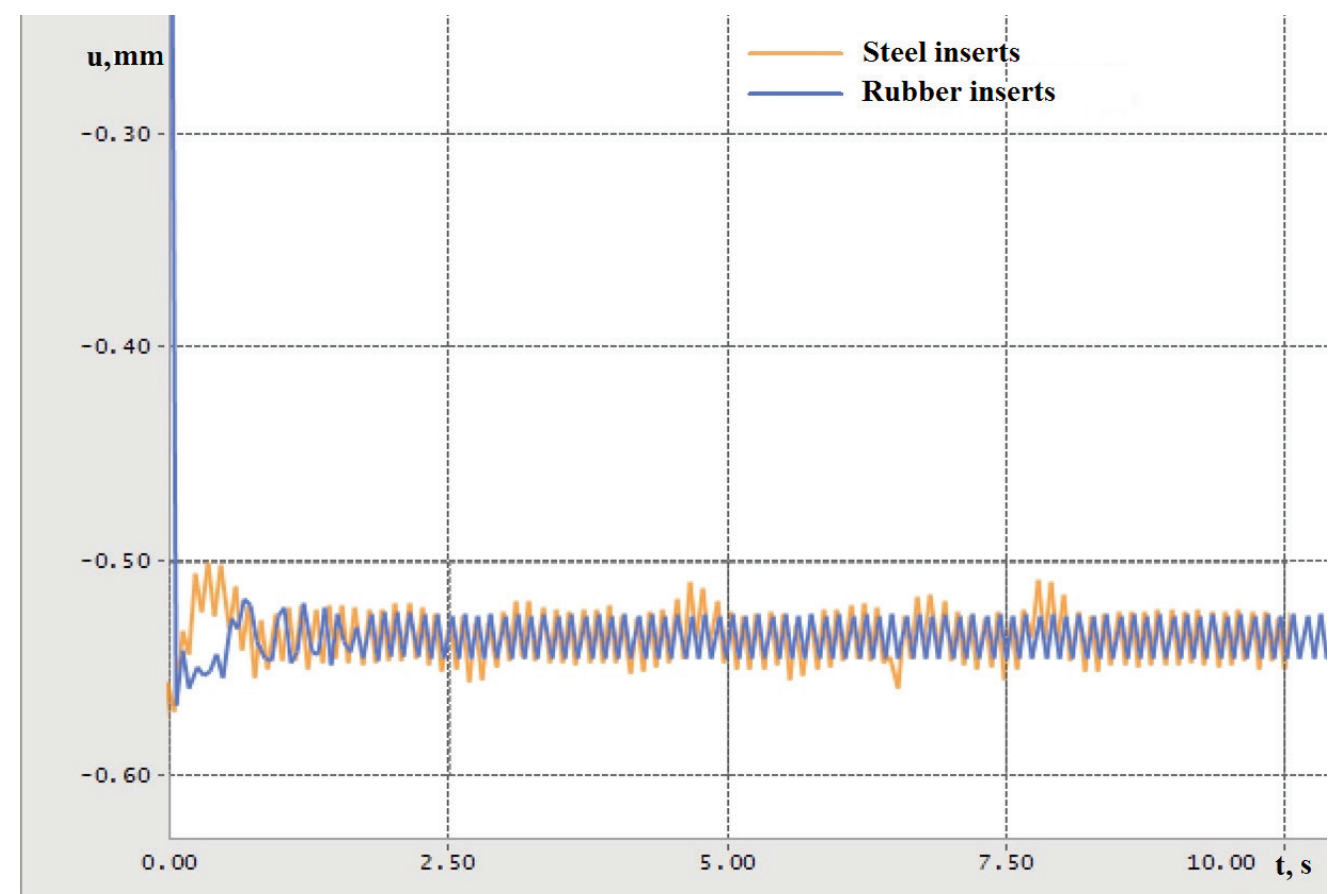

Fig. 5. Comparison of the vibration movements graphs along the Z-axis of the combined face milling cutter with steel and rubber damping elements for modeling face milling in RecyrDun

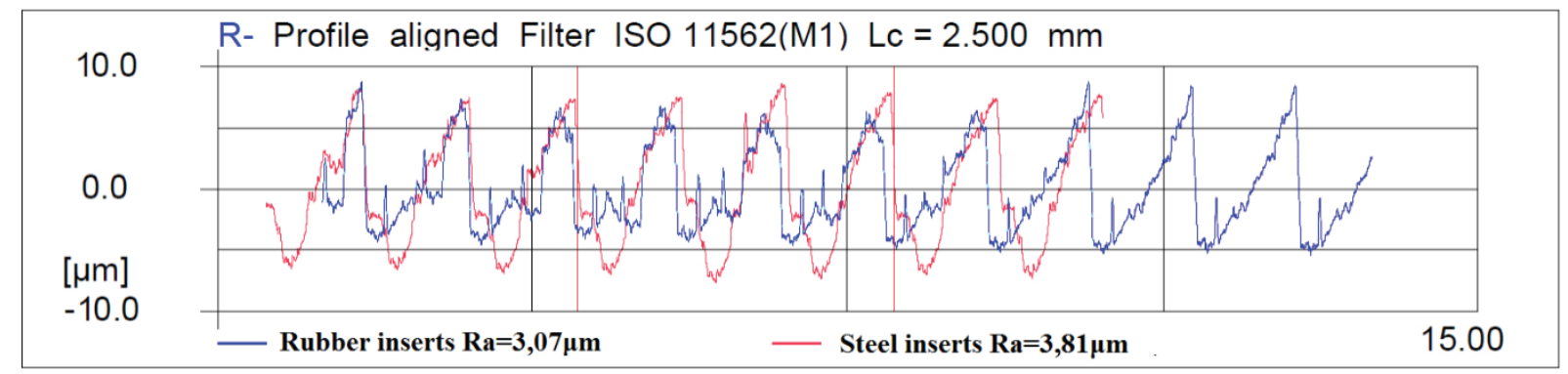

Fig. 6. Oscillograms of measurement on profilograph-profilometer "HOMMEL TESTER W55" roughness Ra of the processed surface when milling with a combined face milling cutter on cutting modes: $\mathrm{t}=1 \mathrm{~mm}, \mathrm{~S}_{\mathbf{M}}=0,1 \mathrm{~mm} / \mathrm{tooth}, \mathrm{V}=188,4 \mathrm{~m} / \mathrm{m}$

\section{References}

1. E. U. Tatarkin, U. A. Kryazhev, E. S. Ognevenko, New aspects of the application of the method of acoustic emission in engineering and metalworking (ASTU, 2015)

2. V. I. Poddubny, U. A. Kryazhev, E. U. Gorin, Development of a 3-D model of a dynamic cutting process with a face mill in RecurDyn. Actual problems in mechanical engineering: III International Scientific and Practical Conference (2016)

3. RecurDyn. Professional Multi Flexible Body Dynamics Simulation Software

[Electronic resource]. URL:

http://functionbay.co.kr/pdf/brochure e web.pdf 